NOTAS DE LEITURA 


\section{PARA UMA HISTÓRIA DA LINGÜÍSTICA NO BRASIL}

José Borges Neto*

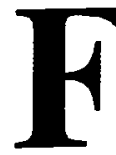

inalmente aparece em forma de livro a tese de doutorado de Cristina Altman, defendida na USP em $1993^{1}$. Se, rigorosamente falando, não se trata do primeiro texto a fazer História da Lingüística no Brasil, creio que se trata da primeira obra a tentar dar uma interpretação dessa história com base nas modernas metodologias de história da ciência. Nesse sentido, o livro de Altman é fundamental não só para o entendimento dos rumos, encontros e desencontros da lingüística no Brasil como para a instauração de uma linha de pesquisas em historiografia da lingüística em nosso país.

O livro contém 11 capítulos, dois apêndices e os vários índices de regra. Há ainda uma Nota Prévia, da autora, e o Prefácio, assinado pelo Prof. Ataliba Teixeira de Castilho, que além de prefaciador, foi examinador da tese que deu origem ao livro (e é importante personagem dele).

Nas palavras de Castilho (trecho do prefácio reproduzido na contracapa):

O livro que se vai ler revela, em páginas densas, porém elegantemente escritas, por que a Lingüística Brasileira é como é.

* Universidade Federal do Paraná

1 ALTMAN, Crsitina. A pesquisa lingïística no Brasil(1968-1988). São Paulo: Humanitas / FFLCH-USP, 1998. 380 p. 
Indiretamente, ele propõe a instalação da Historiografia da Lingüística em nosso meio, e este será, estou seguro, mais um de seus méritos.

\section{O conteúdo do livro}

O capitulo I nos traz uma discussão metodológica sobre a historiografia da linguiística. É o capítulo em que se definem as categorias e as "visadas" que serão projetadas sobre os dados fatuais com vistas à sua interpretação histórica.

A metodologia utilizada por Cristina Altman foi desenvolvida por Pierre Swiggers, da Universidade de Leuven, a partir da noção de paradigma de Thomas Kuhn e da noção de grupos de especialidade de Stephen Murray. $\mathrm{O}$ procedimento básico para a descrição do processo histórico consiste em acompanhar a formação dos grupos de especialidade (grupos de pesquisadores que realizam pesquisas aparentadas, lêem os mesmos autores, citam-se mutuamente, publicam nas mesmas revistas etc.) e em descrever as relações que se estabelecem entre cada um desses grupos e os grupos contemporâneos, bem como as alterações internas e os processos de substituição de um grupo por outro na linha do tempo. Num certo sentido, cada grupo de especialidade é uma comunidade e as diretrizes científicas compartilhadas constituirão um paradigma.

Instrumentada por esta metodologia, Altman, no capítulo II, caracteriza os grupos dominantes no período pré-68 no Brasil. Mostra-nos que o paradigma dominante era o da Filologia (incluídas aí a lingüística histórica e a dialetologia) e que nessa comunidade científica não havia lugar para uma lingüística (entendida como estudo da sincronia).

No capítulo III, Altman discorre sobre os outsiders do paradigma filológico que, no pré-68, insistiam em ser vistos como "lingüistas" e que nem sempre mantinham relações amistosas com a comunidade dominante. Entre os "lingüistas", o grande destaque é dado a Mattoso Câmara Jr, que juntamente com Aryon Rodrigues, introduziu a perspectiva estruturalista nos estudos lingüísticos no Brasil.

Ainda no capítulo III, Altman descreve a situação geral das universidades brasileiras no periodo e as características dos cursos de Letras que, fundamentalmente, constituiam-se no único "mercado" disposto a "consumir" estudos da linguagem. Merece destaque ainda o papel que o primeiro programa de pósgraduação (Universidade de Brasília - 1963) teve na formação de lingüistas voltados ao trabalho de campo numa tradição de pesquisa eminentemente estruturalista. 
Já no capítulo IV, encontramos uma descrição das primeiras relações mais consistentes (relações esporádicas e informais existiam há muito mais tempo) entre a lingüística nascente e a antropologia, a filosofia, a sociologia e a psicologia. Fala-se também do período de formulação e de implantação de uma política geral de pós-graduação no Brasil, voltada à formação de pesquisadores e não de professores de lingiuística.

Nos capítulos seguintes (V a IX), Altman analisa detalhadamente os autores, os temas e as orientações teóricas dos textos publicados nas principais revistas de lingüística.

Inicia, no capítulo V, pelas revistas Estudos e Estudos Lingüísticos, ambas publicadas pelo Instituto de Idiomas Yázigi de São Paulo, a primeira entre 1961 e 1964, e a segunda de 1966 a 1968. Segundo a análise, ambas as revistas tinham um caráter fortemente não-teórico, de um ponto de vista estritamente lingüístico, com muitas incursões nas questões metodológicas do ensino de línguas.

No Capítulo VI, analisa as contribuições feitas à Revista Brasileira de Lingüística, publicada pela Sociedade Brasileira de Professores de Lingüística (SBPL) entre 1974 e 1984. Neste capítulo, Altman mostra que os primeiros grupos de especialidade a se reconhecerem como "lingüistas" utilizaram a revista como lugar privilegiado para suas publicações. Começa a haver uma preocupação crescente com a teorização e o grande tema de discussão é a necessidade de substituir o paradigma da gramática "tradicional", tanto enquanto meio de descrição como de prática pedagógica, por alguma das teorias emergentes, sem haver, no entanto, acordo sobre qual seria essa teoria substitutiva: gerativismo, alguma das versōes do estruturalismo, gramáticas lógicas, gramática construtural etc. Em outras palavras, o que a análise das contribuições feitas à RBL revela é que já existe uma consciência de "comunidade" entre os lingüistas, sem que as escolhas teóricas mais finas estejam definidas: sabe-se o que não se é sem que se saiba exatamente o que se é.

O capítulo VII analisa as contribuições aos Cadernos de Estudos Lingüísticos, publicados pelo Instituto de Estudos da Linguagem da UNICAMP desde 1978. O capítulo VIII analisa as contribuições feitas aos Cadernos de Lingüística e Teoria da Literatura, particularmente aos Ensaios de Lingüística, publicados na UFMG desde 1978. E, finalmente, no capítulo IX, analisam-se as contribuições feitas na revista Documentação de Estudos em Lingüística Teórica e Aplicada (DELTA), publicada pela PUC-SP, desde 1985 (com o patrocínio da ABRALIN, desde 1988). Com a análise desses três periódicos, Altman nos mostra o processo de consolidação de alguns grupos de especialidade e o 
BORGES NETO, j. Para uma história da lingüística no Brasil

surgimento das críticas mútuas, conflitos, propostas de fusão de paradigmas e do surgimento de novos paradigmas.

No capítulo X, Altman faz uma síntese do que ela chama de "Os primeiros 25 anos da Lingüística no Brasil", usando os dados coletados e analisados nos capitulos anteriores para mostrar a trajetória dos estudos lingüísticos em nosso país. Altman mostra a grande mudança de atitude da comunidade, que se vai encontrar nos anos 70 , que embora se considere profissionalmente "lingüista" ainda não se distingue muito claramente nem dos antecessores nem dos contemporâneos. Sobre esse período, Altman afirma:

A tônica do momento era a diversificação. A multiplicidade se refletiu, em primeiro lugar, nos tipos de artigos veiculados pelos periódicos. A proporção entre artigos programáticos - que propunham um 'novo' modelo ou um 'novo' tipo de investigação; artigos de crítica - que refutaram, total ou parcialmente analises já feitas e que, no lugar, propuseram outra; e artigos de pesquisa - que simplesmente aplicavam um modelo, é bastante diferente na década de setenta, em relação às décadas de sessenta ou oitenta.

Nos anos 60, o predomínio era de artigos de pesquisa, revelando que os lingüistas brasileiros estavam receptivos às teorias alienígenas, mas que não refletiam criticamente sobre elas: é um período de reconhecimento das potencialidades das teorias. Nos anos 70 , temos a proliferação dos artigos programáti$\cos (21 \%$ dos textos publicados nos periódicos investigados eram programáticos), indicando uma busca de refinamento teórico e, agora sim, uma consolidação de grupos de especialidade mais maduros. Nos anos 80 , encontramos um aumento no número de artigos de pesquisa e uma grande queda no número de artigos programáticos (que passam a ser apenas $6 \%$ dos artigos publicados), o que revela a estabilização dos grupos de especialidade que, definida a base teórica, podem dedicar-se à análise dos dados lingüísticos (à prática da "ciência normal", nos termos de Kuhn).

O capítulo XI do livro de Cristina Altman é um capítulo de conclusão em que a autora desenvolve comentários sobre duas conclusões gerais:

a) a emergência de uma prática 'lingüística', em oposição a uma prática 'filológica', se traduziu de maneira geral, no contexto brasileiro, pela oposição criada sempre entre dois eixos, tais 
como: filologia $x$ lingüística; texto $x$ sentença; diacronia $x$ sincronia; descrição $x$ explicação; Europa $x$ Estados Unidos;

b) a produção lingüística brasileira se desenvolveu ao longo do periodo em foco pela valorização e preferência pela análise sincrônica, explicativa e formal dos componentes da sentença (p. 295-296).

Altman deixa claro que o peso maior ou menor de cada pólo dos vários eixos varia de intensidade ao longo do período e que essa ponderação também varia entre os grupos de especialidade. As oposições, no entanto, permanecem constantes durante todo o período.

Os apêndices do livro trazem uma listagem dos artigos analisados, organizados por periódico e por autor, (apêndice 1) e um mapeamento da produção do período tendo em vista a temática e a orientação predominante (apêndice 2). Os apêndices revelam-se muito úteis no acompanhamento da argumentação da autora e certamente poderão servir de ponto de partida para outros trabalhos sobre o período.

\section{A metodologia}

A metodologia adotada por Altman revela-se extremamente adequada ao tratamento do período escolhido.

De forma geral, as metodologias de História da Ciência trabalham com "teorias" ou com "comunidades" mais ou menos bem estabelecidas. Por exemplo, Kuhn e Lakatos analisam o desenvolvimento de uma ciência a partir do (eventualmente reiterado) surgimento de "paradigmas" (para Kuhn) ou "programas de investigação" (para Lakatos) em contraposição a outros paradigmas (ou programas de investigação) já existentes. No momento da consolidação de uma ciência particular (no momento do surgimento do primeiro paradigma ou primeiro programa de investigação), o que encontrariamos seria um cientista "genial" propondo uma teoria que fosse vista como potencialmente interessante pelos contemporâneos que, abandonando as práticas prévias passam a engrossar a nova comunidade.

Obviamente, o caso brasileiro não se enquadra facilmente em nenhuma dessas categorias. Nem tivemos um caso clássico de conflito entre paradigmas, nem foi o caso de se fazerem propostas teóricas inovadoras que levaram à substituição de paradigmas. Os verdadeiros conflitos entre os paradigmas que estavam em jogo na cena da lingüística brasileira nos anos 60,70 e 80 já haviam 
se dado em outros lugares e em outros tempos (perspectiva filológica já havia sido desbancada pelo estruturalismo no início do século, a partir do trabalho de Saussure e de suas repercussões, e o próprio estruturalismo já tinha suas posições sob o fogo cerrado dos adeptos do gerativismo desde o final dos anos 50).

Simplesmente, não podemos abordar o caso brasileiro a partir de noções como "Revolução Científica" porque vivíamos aqui um caso de revolução "requentada". $\mathrm{Na}$ verdade, o que tivemos foi simplesmente um processo de "atualização", com a comunidade dos "lingüistas" brasileiros tentando "acertar o passo" com os lingüistas europeus e americanos. Ou, para ser mais preciso, o que tivemos foi o surgimento de uma nova geração de estudiosos da linguagem, descomprometida com a tradição dos estudos filológicos, e voltada para o que de mais recente se fazia na Europa e nos Estados Unidos.

O período analisado por Altman não é um período em que se verifiquem conflitos ideológicos relacionados com os fazeres científicos de um ponto de vista interno. Não eram as teorias que estavam em jogo. No caso brasileiro, o que estava em jogo eram as práticas. Os conflitos, então, devem ser vistos de um ponto de vista externo. Se há uma "revolução" no Brasil dos anos 60 , ela é de doxa e não de episteme.

Consciente disso, e atenta aos fatos e às necessidades explicativas que esses fatos demandam, Cristina Altman vai utilizar uma metodologia historiográfica que nos permite tratar a dimensão externa do desenvolvimento científico, sem cair na mera crônica (risco que correm as "histórias externas"). A metodologia dos "programas de investigação" de Swiggers, talvez até em virtude de suas deficiências ${ }^{2}$, revelou-se à altura do empreendimento.

O apelo à noção de "grupos de especialidade", noção oriunda da Sociologia da Ciência e descendente direta da noção de "Invisible College", e a demonstração de que é possível acompanhar o processo de formação desses grupos na comunidade brasileira a partir das publicações em nossos periódicos (poucos e irregulares, infelizmente), embora não necessariamente ligado à metodologia de Swiggers, enriqueceu notavelmente o resultado final do trabalho.

2 Num certo sentido, a metodologia de Swiggers simplesmente retoma, e torna vagos, os conceitos fundamentais da metodologia dos programas de investigação científica de Imre Lakatos, permitindo a incorporação dos dados extemos ao modelo explicativo, dados que na metodologia de Lakatos (essencialmente internalista) são tratados em paralelo. 


\section{Conclusão}

O livro de Cristina Altman, por meio de uma análise detalhada, e adequadamente fundamentada, nos revela o longo e tortuoso processo de implantação dos estudos lingüísticos "modernos" na academia brasileira. Simultaneamente, exemplifica o que poderia ser um modo adequado de se fazer história da linguística num contexto de diversificação ideológica como o que vivíamos no Brasil na década de 60 . O resultado é um livro riquíssimo em informações, tanto fatuais quanto metodológicas.

Creio que o livro, pela sua importância inerente e pelo pioncirismo, merecia um tratamento gráfico mais cuidadoso, principalmente com relação à capa (quase ilegível, em função de uma péssima composição de cores e de fontes de letras). De qualquer forma, trata-se de um livro imperdível para quem quer saber mais sobre como funcionam as academias e para quem quer saber porque a lingüística que se faz no Brasil tem as características que tem. Um livro imperdível para quem faz (ou gostaria de fazer) história da lingüística.

Lisboa, fevereiro de 1999. 